\title{
INVESTIGATION INTO MOTIVATION: SIGNIFICANCE, TYPES AND THEORIES
}

\author{
Atul kumar \\ Assistant Professor (Guest Faculty), Jananayak Chandrashekhar university, Ballia
}

Article DOI: https://doi.org/10.36713/epra5993

\begin{abstract}
Motivation plays a vital role in execution of work. It refers to those vibes that pushes a person at work to use his potentialities to perform for the achievement of his personal or organisational goals. Every individual perform activities to get something in return. The level of motivation affects individuals performances if he is highly motivated he would try to achieve his objectives in most efficient and rapid ways. This paper tries to highlight the significance, Extrinsic and intrinsic types of motivation and theories of motivation. This Paper focuses on the intrinsic and extrinsic motivation and give detailed information about different theories of motivation. In organisations managers try to motivate their employees so they can utilise their potentials in best possible ways.
\end{abstract}

KEYWORDS: Motivation, intrinsic, extrinsic, Employee Performance, Motivation Theory

\section{INTRODUCTION}

Motivation may be outlined because the complexness of forces that conjures up an individual at work to accentuate his needs and temperament to use his potential to perform so as to realize structure objectives. in step with Mile (2004), motivation could be a condition that influences the arousal, direction and maintenance of behavior. Human desires should be happy, and this could cause the arousal of psychological feature forces. Koontz et al. (1990) opined that motivation of staff is a very important inner management tool and will be happy so as to achieve blessings like magnified worker commitment, magnified productivity and potency. Motivation emphasizes result-oriented management through the setting of sensible goals and effective communication systems in a corporation. According to Koontz et al. (1990), worker performance refers to the potency and effectiveness of staff in achieving structure goals and objectives. They more declared that worker performance can be evaluated by considering the amount of absence, quality of reports, and therefore the time of coverage for and departure duty.

\section{OBJECTIVES OF THE STUDY}

1. To know the significance of employee motivation.

2. To know the Extrinsic and Intrinsic motivation

3. To know the theories of motivation.

\section{SIGNIFICANCE OF EMPLOYEE MOTIVATION}

Motivation is one of the vital components that assist a man with succeeding and accomplish his own objectives. A roused individual can outline a course to progress and in the long run self-advancement. At whatever point quite an individual deals with something incomprehensible, he places in his central core to make it conceivable. Other than his aptitudes, information, and experience, his inspiration likewise assumes a fundamental part in this undertaking. It is hence, organizations and associations pay attention to their workers inspiration very.

studies have plainly demonstrated a nearby between connection among inspiration and execution. A propelled representative performs obviously better than an unmotivated one. It is on the grounds that at whatever point he goes over an undertaking that is truly important and critical, he chips away at it with complete commitment to finish past his own desires.

Numerous representatives don't feel as inspired true to form in their positions since they think that its dull, redundant, and dreary. It hoses their soul and doesn't feel slanted to complete the work or finish it only for the hell of it. Such associations can't dream to push ahead, progress, and thrive in their picked spaces as their HR do not have the soul. The opportunity has arrived to zero in on this issue and make remedial moves that assist representatives with feeling inspired. Basically, for 
each organization and business, inspiration is the way to make phenomenal progress. The advantages got from having a propelled employees are immense.

\section{EXTRINSIC AND INTRINSIC MOTIVATION \\ 4.1 Extrinsic Motivation}

Outward inspiration alludes to inspiration that comes from outside a person. The spurring factors are outer, or outside, prizes, for example, cash or evaluations. These rewards give fulfilment and joy that the errand itself may not give. An extraneously persuaded individual will deal with an assignment in any event, when they have little interest in it due to the foreseen fulfilment they will get from some prize. The prizes can be something as minor as a smiley face to something significant like acclaim or fortune. For instance, an extraneously persuaded individual who despises math may buckle down on a numerical statement since he needs the compensation for finishing it. On account of an understudy, the prize would be a passing mark on a task or in the class.

Extraneous inspiration doesn't mean, nonetheless, that an individual won't get any joy from dealing with or finishing an errand. It just implies that the joy they foresee from some outer prize will keep on being a help in any event, when the undertaking to be done holds almost no interest. An extraneously persuaded understudy, for instance, may loathe a task, may think that its exhausting, or may have no interest in the subject, however the probability of a passing mark will sufficiently be to keep the understudy inspired all together for that person to invest the energy to excel on an assignment.

Extrinsic motivation is probably going to include the idea of remunerated conduct. Accordingly, by participating in a specific kind of action or carrying on in a specific way, you are "remunerated" by an ideal final product. For example, you are spurred to set aside cash for a getaway. Subsequently, you oppose the desire to make hasty buys and by and large become additionally separating in how you go through your cash. After a period you find that you have a consistently developing measure of reserve funds which you put in a safe spot. At the point when you find that you have saved enough for that trip, you use your reserve funds for the planned reason and take some time off. The outer inspiration is the excursion, which is additionally the prize for your demonstration of putting something aside for it.

\subsection{Intrinsic Motivation}

Intrinsic Motivation alludes to inspiration that comes from inside an individual as opposed to from any outer or outside remunerations, for example, cash or evaluations. The inspiration comes from the joy one gets from the assignment itself or from the sense of fulfillment in finishing or in any event, dealing with an assignment. A characteristically inspired individual will deal with a numerical problem, for instance, since it is charming. Or on the other hand a naturally inspired individual will deal with an answer for an issue since the test of finding an answer is gives a feeling of joy. In not one or the other case accomplishes the individual work on the errand on the grounds that there is some prize included, for example, a prize, an installment, or on account of understudies, an evaluation. Characteristic inspiration doesn't mean, nonetheless, that an individual won't look for remunerations. It just implies that such outer prizes are sufficiently not to keep an individual propelled. An inherently inspired understudy, for instance, might need to get a passing mark on an task, yet in the event that the task doesn't intrigue that understudy, the chance of a decent grade isn't sufficient to keep up that understudy's inspiration to invest any energy into the venture. Characteristic inspiration is something contrary to extraneous inspiration. That last kind of inspiration comes from outside of you. Yet, natural inspiration comes from inside the person. So to comprehend the instances of characteristic inspiration, it assists with considering it motivation. Yet, we could state that extraneous inspiration is practically equivalent to "incitement" all things considered. When you are outwardly persuaded, you are accomplishing something that you may Sorts of Motivation very well not have any desire to do, or not be too intrigued by. What you're doing resembles a task. Be that as it may, instances of natural inspiration will consistently be works of adoration. Maybe you are considering something in school that you truly discover exhausting or simply don't care about, yet you would like to get passing marks. Or then again, maybe you take an employment in deals since there is potential for some extremely high commissions, however you really disdain deals These are occurrences of outward inspiration. Some of the time, the majority of us should concede, we likewise don't do things that we might want to do, since doing so would mean we violated the law and we could be punished for that. For example, not driving our vehicle as quick as we may like is a genuine illustration of this. This shirking would be outward inspiration also.

\section{THEORIES OF MOTIVATION}

Various theories of Motivation Provided by Different Authors. Some of well known theories of motivation are as following:

\subsection{Maslow's Need Hierarchy Theory}

Human inspiration can be characterized as the satisfaction of different requirements. These requirements can envelop a scope of human cravings, from essential, unmistakable necessities of endurance to intricate, feelings encompassing a person's mental prosperity. Abraham Maslow was a social therapist who was keen on an expansive range of human 
mental requirements as opposed to on individual mental issues. He is most popular for his chain of importance of-needs hypothesis. Portrayed in a pyramid the hypothesis puts together the various degrees of human mental and actual requirements arranged by significance.

A triangle is partitioned vertically into five areas with relating names inside and outside of the triangle for each segment. Start to finish, the triangle's areas are marked: "self-realization" compares to "Internal satisfaction" "regard" relates to "Self-esteem, achievement, certainty"; "social" compares to "Family, companionship, closeness, having a place"' "security" compares to "Wellbeing, work, resources"; ""physiological" relates to "Food, water, cover, warmth."

Maslow's progression of necessities is shown here. In certain forms of the pyramid, psychological and stylish requirements are additionally included among regard and self-completion. Others incorporate one more level at the highest point of the pyramid for self-amazing quality.

The needs in Maslow's order incorporate physiological requirements (food and garments), wellbeing needs (employer stability), social necessities (companionship), confidence, and selfcompletion. This chain of importance can be utilized by supervisors to all the more likely comprehend representatives' necessities and inspiration and address them in manners that lead to high efficiency and employment fulfillment.

At the lower part of the pyramid are the physiological (or fundamental) human necessities that are needed for endurance: food, cover, water, rest, and so on On the off chance that these necessities are not met, the body can't keep on working. Confronted with an absence of food, love, and security, the vast majority would presumably believe food to be their most critical need.

When actual requirements are fulfilled, security (now and again alluded to as individual wellbeing) outweighs everything else. Security and wellbeing needs incorporate individual security, monetary security, and wellbeing and prosperity. These initial two levels are imperative to the actual endurance of the individual. When people have fundamental nourishment, sanctuary, and security, they look to satisfy more elevated level requirements.

The third level of need is social, which incorporates love and having a place; when people have dealt with themselves actually, they can deliver their need to share and associate with others. Inadequacies at this level, because of disregard, evading, shunning, and so forth, can affect a person's capacity to shape and keep up sincerely critical connections. People need to feel a feeling of having a place and acknowledgment, regardless of whether it comes from a huge social gathering or a little organization of loved ones. Different wellsprings of social association might be proficient associations, clubs, strict gatherings, online media destinations, etc. People need to cherish and be adored (explicitly and non-explicitly) by others. Without these connections, individuals can be helpless against mental challenges, for example, forlornness, social uneasiness, and misery. These conditions, when serious, can disable an individual's capacity to address fundamental physiological necessities, for example, eating and resting.

The fourth level is esteem, which speaks to the typical human craving to be esteemed and approved by others, through, for instance, the acknowledgment of achievement or status. This level likewise incorporates confidence, which alludes to the respect and acknowledgment one has for oneself. Irregular characteristics at this level can bring about low confidence or a feeling of inadequacy. Individuals experiencing low confidence may locate that outside approval by others - through notoriety, wonder, honors, and so on-just halfway or briefly satisfies their requirements at this level.

At the highest point of the pyramid is selfactualization. At this stage, individuals feel that they have arrived at their maximum capacity and are doing all that they're able to do. Self-realization is once in a while a perpetual inclination or state. Or maybe, it alludes to the continuous requirement for self-awareness and disclosure that individuals have for the duration of their lives. Self-realization may happen subsequent to arriving at a significant objective or defeating a specific test, and it could be set apart by another self-appreciation certainty or satisfaction.

\subsection{Alderfer's ERG Theory}

Clayton Paul Alderfer is an American analyst who built up Maslow's chain of importance of requirements into a hypothesis. Alderfer's ERG hypothesis proposes that there are three gatherings of center necessities: presence $(\mathrm{E})$, relatedness $(\mathrm{R})$, and development $(\mathrm{G})$ - henceforth the abbreviation ERG. These gatherings line up with Maslow's degrees of physiological requirements, social necessities, and self-completion needs, individually.

Existence needs concern our fundamental material prerequisites for living. These incorporate what Maslow arranged as physiological requirements, (for example, air, food, water, and asylum) and wellbeing related necessities, (for example, wellbeing, secure work, and property).

Relatedness needs have to do with the significance of keeping up relational connections. These necessities are situated in social collaborations with others and line up with Maslow's degrees of affection/having a place related requirements, (for example, kinship, family, and sexual closeness) and regard related requirements (picking up the admiration of others). 
At long last, growth needs to portray our characteristic craving for self-improvement. These necessities line up with the other part of Maslow's regard related requirements (confidence, fearlessness, and accomplishment) and self-realization needs, (for example, profound quality, innovativeness, critical thinking, and revelation).

Alderfer suggested that when a specific class of necessities isn't being met, individuals will try harder to satisfy needs in a lower classification. For instance, if somebody's confidence is enduring, the individual will put more exertion in the relatedness classification of necessities.

\subsection{Mcclelland's Acquired Needs Theory}

Psychologist David McClelland's acquired needs theory splits the needs of workers into three classes instead of the two we examined in Herzberg's theory. These three classifications are achievement, affiliation, and power.

employees who are unequivocally achievement persuaded are driven by the craving for dominance. They lean toward dealing with errands of moderate trouble in which results are the consequence of their work as opposed to karma. They esteem accepting input on their work.

Workers who are firmly association spurred are driven by the craving to make and keep up social connections. They appreciate having a place with a gathering and need to feel cherished and acknowledged. They may not make powerful directors since they may stress a lot over how others will feel about them.

Workers who are firmly power-spurred are driven by the craving to impact, educate, or empower others. They appreciate work and spot a high incentive on order. Notwithstanding, they may adopt a lose-lose strategy to assemble work-for one individual to win, or succeed, another should lose, or fizzle. Whenever diverted fittingly, however, this methodology can decidedly uphold bunch objectives and help other people in the gathering feel skilled.

The gained needs hypothesis doesn't guarantee that individuals can be perfectly ordered into one of three kinds. Or maybe, it declares that all individuals are inspired by these requirements in changing degrees and extents. A person's equilibrium of these requirements shapes a sort of profile that can be valuable in making a custom-made inspirational worldview for her. Note that requirements don't really correspond with capabilities; it is feasible for a representative to be firmly association persuaded, for instance, yet be fruitful in a circumstance in which her alliance needs are not met.

McClelland recommends that those in top administration positions for the most part have a significant requirement for power and a low requirement for connection. He additionally accepts that despite the fact that people with a requirement for accomplishment can make great chiefs, they are not for the most part fit to being in top administration positions.

\subsection{McGregor's Theory $X$ and Theory $Y$}

The possibility that an administrator's demeanor affects worker inspiration was initially proposed by Douglas McGregor, an administration teacher at the Massachusetts Institute of Technology during the 1950s and 1960s. In his 1960 book, The Human Side of Enterprise, McGregor proposed two speculations by which chiefs see and address worker inspiration. He alluded to these contradicting inspirational techniques as Theory $\mathrm{X}$ and Theory $\mathrm{Y}$ the executives. Each accepts that the chief's job is to arrange assets, including individuals, to best profit the organization. Nonetheless, past this shared characteristic, the mentalities and suspicions they exemplify are very unique.

\section{Theory $\mathbf{X}$}

Theory $\mathrm{X}$ is based on the following assumptions: 1. People are by nature indolent. That is, they like to work as little as possible.

2. People lack ambition, dislike responsibility, and prefer to be directed by others.

3. People are inherently self-centered and indifferent to organisational needs and goals.

4. People are generally gullible and not very sharp and bright.

Essentially, Theory $\mathrm{X}$ expects that the essential wellspring of representative inspiration is money related, with security as a solid second. Under Theory X, one can adopt a hard or delicate strategy to getting results. The hard way to deal with inspiration depends on pressure, certain dangers, micromanagement, and tight controls - basically a climate of order and control. The delicate methodology, notwithstanding, is to be tolerant and look for congruity in the expectations that, consequently, workers will coordinate when inquired. Be that as it may, neither of these limits is ideal. The hard methodology brings about antagonism, intentionally low yield, and extraordinary association requests. The delicate methodology brings about a developing craving for more noteworthy award in return for lessened work yield.

It may appear to be that the ideal way to deal with human asset the executives would lie somewhere close to these limits. Nonetheless, McGregor states that neither one of the approaches is fitting, since the fundamental suppositions of Theory $\mathrm{X}$ are mistaken.

Persuade anymore on Maslow's progressive system of necessities, McGregor contends that a need, when fulfilled, does not spurs. The organization utilizes money related rewards and advantages to fulfill workers' lower-level necessities. When those necessities have been fulfilled, the inspiration vanishes. Hypothesis $\mathrm{X}$ administration obstructs the fulfillment of more significant level requirements since it doesn't recognize that those necessities are 
important in the working environment. Subsequently, the solitary way that representatives can endeavor to meet more elevated level requirements at work is to look for more remuneration, in this way, typically, they center around money related prizes. While cash may not be simply the best way satisfaction, it very well might be the lone way accessible. Individuals will utilize work to fulfill their lower needs and look to fulfill their higher requirements during their recreation time. Be that as it may, representatives can be most gainful when their work objectives line up with their more elevated level requirements.

McGregor mentions that an order and-control climate isn't powerful on the grounds that it depends on lower needs for inspiration, yet in present day culture those necessities are generally fulfilled and accordingly are done spurring. In the present circumstance, one would anticipate that representatives should disdain their work, keep away from duty, have no interest in authoritative objectives, oppose change, and so forth-making, as a result, an unavoidable outcome. To McGregor, a consistent stockpile of inspiration appeared to be bound to happen under Theory Y the board.

\section{Theory $\mathbf{Y}$}

The more elevated level requirements of regard and self-realization are continuous necessities that, for a great many people, are rarely totally fulfilled. Thusly, it is these more elevated level requirements through which representatives can best be inspired. In solid difference to Theory X, Theory $\mathrm{Y}$ the board makes the accompanying suppositions: Work can be as normal as play if the conditions are ideal. Individuals will act naturally coordinated and inventive to meet their work and hierarchical goals in the event that they are focused on them. Individuals will be focused on their quality and efficiency targets if rewards are set up that address higher requirements, for example, self-satisfaction. The limit with respect to inventiveness spreads all through associations. A great many people can deal with duty since imagination and creativity are normal in the populace. Under these conditions, individuals will look for obligation.

these presumptions, there is an occasion to adjust individual objectives to authoritative objectives by utilizing the worker's own requirement for satisfaction as the help. McGregor focused on that Theory Y the executives doesn't infer a delicate methodology. McGregor perceived that a few people might not have arrived at the degree of development expected by Theory $\mathrm{Y}$ and may at first need more tight controls that can be loose as the worker creates.

In the event that Theory Y remains constant, an association can apply the accompanying standards of logical administration to improve representative inspiration: Decentralization and appointment: If firms decentralize control and diminish the quantity of levels of the executives, supervisors will have more subordinates and thus need to assign some obligation and dynamic to them. Occupation amplification: Broadening the extent of a worker's employment mixes it up and occasions to fulfill conscience needs. Participative administration: Consulting representatives in the dynamic cycle taps their innovative limit and furnishes them with some command over their workplace. Execution examinations: Having the representative set destinations and take an interest during the time spent self-assessment expands commitment and devotion. On the off chance that appropriately executed, such a climate can increment and consistently fuel inspiration as representatives work to fulfill their more significant level individual necessities through their positions.

\subsection{Herzberg's Two-Factor Theory}

American clinician Frederick Herzberg is viewed as one of the incredible unique masterminds in administration and persuasive hypothesis. Herzberg set out to decide the impact of demeanor on inspiration, by essentially requesting that individuals portray the occasions when they felt great, and truly downright awful, their positions. What he discovered was that individuals who had a positive outlook on their positions gave altogether different reactions from the individuals who felt terrible.

The outcomes from this request structure the premise of Herzberg's Motivation-Hygiene Theory (once in a while known as Herzberg's "Two Factor Theory"). Distributed in his renowned article, "Once again: How would You Motivate Employees," the ends he drew were uncommonly compelling, and still structure the bedrock of good persuasive practice almost 50 years after the fact. He's particularly perceived for his two-factor hypothesis, which guessed that are two distinct arrangements of elements administering position fulfillment and employment disappointment: "cleanliness factors," or extraneous inspirations and "inspiration factors," or inborn helpers.

Cleanliness factors, or extraneous sparks, will in general speak to more substantial, essential necessities-i.e., the sorts of requirements remembered for the presence class of requirements in the ERG hypothesis or in the lower levels of Maslow's order of necessities. Outward helpers incorporate status, employer stability, compensation, and incidental advantages. It's significant for supervisors to understand that not giving the suitable and expected extraneous sparks will plant disappointment and reduction inspiration among representatives.

Inspiration factors, or inherent helpers, will in general speak to less unmistakable, more feelingsi.e., the sorts of necessities distinguished in the "relatedness" and "development" classifications of requirements in the ERG hypothesis and in the more significant levels of Maslow's chain of importance of 
necessities. Natural inspirations incorporate testing work, acknowledgment, connections, and development potential. Administrators need to perceive that while these necessities may fall outside the more conventional extent of what a working environment should give, they can be basic to tough individual and group execution.

The factor that separates two-factor hypothesis from the others we've examined is the job of worker desires. As indicated by Herzberg, inherent inspirations and outward sparks have an opposite relationship. That is, inborn helpers will in general expand inspiration when they are available, while outward sparks will in general diminish inspiration when they are missing. This is because of workers' desires. Outward inspirations (e.g., compensation, benefits) are normal, so they won't expand inspiration when they are set up, however they will cause disappointment when they are absent. Natural inspirations (e.g., testing work, development potential), then again, can be a wellspring of extra inspiration when they are accessible.

\section{REFERENCES}

1. Benabou, R. and Tirole, J. (2003) 'Intrinsic and extrinsic motivation'. The Review of Economic Studies

2. Maslow, A. (1943). A theory of human motivation. New York: Harper \& Row.

3. Alderfer, C.P. (1969). 'An Empirical Test of a New theory of Human Needs'. Organizational Behaviour and Human Performance.

4. McClelland, D. C. (1971). Assessing Human Motivation. Morristown, NJ: General Learning Press.

5. McGregor, D. (1960) The Human Side of Enterprise. 1st ed. New York: McGraw-Hill.

6. Herzberg, T. (2000). Job satisfaction and employee performance, 8th edition. Oxford: Oxford University Press 